09,04

\title{
Двухфотонное возбуждение антистоксовой фотолюминесценции кристаллов $\mathrm{Ca}_{1-x} \mathrm{Er}_{x} \mathrm{~F}_{2+x}$
}

\author{
(C) А.Н. Грузинцев ${ }^{1}$, Д.Н. Каримов ${ }^{2}$ \\ ${ }^{1}$ Институт проблем технологии микроэлектроники и особочистых материалов РАН, \\ Черноголовка, Россия \\ ${ }^{2}$ Федеральный научно-исследовательский центр „Кристаллографрия и фотоника“ РАН, \\ Москва, Россия \\ E-mail: gran@iptm.ru
}

(Поступила в Редакцию 24 мая 2016 г.)

\begin{abstract}
Из расплава методом Бриджмена получены кристаллы состава $\mathrm{Ca}_{1-x} \mathrm{Er}_{x} \mathrm{~F}_{2+x}(0<x \leq 0.02)$. Проведен анализ спектров поглощения, возбуждения люминесценции и фотолюминесценции данного материала при стоксовом и антистоксовом механизме оптического возбуждения одновременно двумя источниками излучения. Обнаружено появление видимой люминесценции при последовательном поглощении двух резонансных инфракрасных фотонов различной энергии. Данный эффект связан с наличием метастабильных состояний возбужденных уровней ${ }^{4} I_{11 / 2}$ ионов $\mathrm{Er}^{3+}$, с которых происходят переходы на более высокие энергетические уровни при поглощении инфракрасных фотонов.
\end{abstract}

DOI: 10.21883/FTT.2017.01.43960.212

\section{1. Введение}

Материалы, легированные ионами редкоземельных элементов (РЗИ), нашли широкое применение в качестве люминофоров, волоконных лазеров и усилителей, устройств оптической памяти и трехмерных дисплеев. Некоторые из РЗИ дают хорошую антистоксовую люминесценцию для визуализации инфракрасного (ИК) света. Повышение эффективности этого типа люминесценции требует использования кристаллических матриц с малой энергией фононов, РЗИ с большими временами жизни метастабильных возбужденных состояний и сечением поглощения этими возбужденными состояниями в ИК-области спектра [1]. Вместе с тем вероятность люминесценции в видимой области с высоко лежащих состояний должна быть большой. Имеется два механизма дальнейшего возбуждения метастабильных возбужденных состояний РЗИ: за счет оптического поглощения второго ИК-фотона и за счет безызлучательной передачи энергии от другого возбужденного редкоземельного иона (например, $\mathrm{Yb}^{3+}$ ) [2]. Во втором случае расстояние между двумя возбужденными ионами должно быть менее $2 \mathrm{~nm}$, что требует высокой концентрации РЗИ в кристалле и больших интенсивностей ИК-возбуждения. Для антистоксовой люминесценции при малых интенсивностях ИК-возбуждения первый механизм является превалирующим, но он требует резонансного совпадения энергий первого и второго фононов с энергетическими расстояниями между уровнями РЗИ.

Фторид кальция $\mathrm{CaF}_{2}$ интересен в качестве объекта исследований не только из-за малой энергии фононов, но и из-за высокой изоморфной емкости по отношению к РЗИ, оптической прозрачности в широком спектральном диапазоне $0.12-10 \mu \mathrm{m}$. Этот материал может быть легко получен в виде объемных кристаллов расплавными ме- тодами или тонких пленок высокого качества методами молекулярно-лучевой [3] или жидкофазной эпитаксии [4]. Для лазерных применений важна легкость введения в состав кристаллов значительных (вплоть до $10^{22} \mathrm{~cm}^{-3}$ ) концентраций активных ионов, их высокая теплопроводность, хорошая механическая прочность и устойчивость к внешним воздействиям. Отметим, что кристаллы фторида кальция, легированные ионами $\mathrm{Er}^{3+}-$ $\mathrm{Ca}_{1-x} \mathrm{Er}_{x} \mathrm{~F}_{2+x}$, обладая хорошими спектральными и генерационными свойствами (богатый спектр поглощения ионов $\mathrm{Er}^{3+}$, четырехуровневая система накачки, большая выходная энергия генерации) являются материалом для создания твердотельного генератора на длинах волн 1.55 и $2.73 \mu \mathrm{m}$ при комнатной температуре [5]. При создании мощных ИК-лазеров антистоксовая люминесценция является вредным эффектом, уменьшающим энергетический выход лазера. Поэтому изучение ее механизмов является актуальной проблемой, требующей более детального изучения.

Имея множество уровней энергии для ионов $\mathrm{Er}^{3+}$, логично предположить, что суммирование энергий ИК-фотонов может быть даже более эффективным для двух фотонов разной энергии, каждый из которых находится в резонансе со своим переходом электрона вверх. Подбирая резонансные длины волн этих двух фотонов, можно получить резкое увеличение интенсивности антистоксовой люминесценции по сравнению с возбуждением фотонами с одной и той же длиной волны, которое обычно используют в эксперименте. Двухлучевое возбуждение среды позволит использовать ее для создания реально трехмерного изображения при сканировании точки пересечения лазерных лучей в пространстве.

Цель настоящей работы - исследование спектров поглощения и возбуждения видимого свечения кристаллов $\mathrm{Ca}_{1-x} \mathrm{Er}_{x} \mathrm{~F}_{2+x}$ с разной концентрацией примеси для 
определения всевозможных резонансных частот двух последовательно поглощаемых ИК-фотонов при антистоксовом механизме люминесценции.

\section{2. Эксперимент}

Кристаллы $\mathrm{Ca}_{1-x} \mathrm{Er}_{x} \mathrm{~F}_{2+x} \quad(x=0.005,0.010,0.020)$ для исследований выращивали методом Бриджмена во фторирующей атмосфере, создаваемой $\mathrm{CF}_{4}$ (чистота 99.999 vol.\%), по методике [6]. В качестве исходных реактивов использовали $\mathrm{CaF}_{2}$ в виде боя оптических кристаллов производства Государственного оптического института (Санкт-Петербург) и порошок $\mathrm{ErF}_{3}$ (чистота 99.99 wt.\%, ООО „Ланхит“). Были получены кристаллические були $\mathrm{Ca}_{1-x} \mathrm{Er}_{x} \mathrm{~F}_{2+x}$ оптического качества диаметром до $15 \mathrm{~mm}$ и длиной до $30 \mathrm{~mm}$. Потери на испарение в процессе выращивания не превышали $0.2 \mathrm{wt} . \%$. Концентрации $\mathrm{Er}^{3+}$ в кристаллах указаны по составу исходной шихты. Образцы для исследований представляли собой шайбы толщиной $5 \mathrm{~mm}$.

Спектры поглощения кристаллов $\mathrm{Ca}_{1-x} \mathrm{Er}_{x} \mathrm{~F}_{2+x}$ регистрировались (в диапазоне $300-1800 \mathrm{~nm}$ ) в видимой и ИК областях спектра с помощью светосильного монохроматора МДР-12 и фотоприемников ФЭУ-106 и ФЭУ-62. При этом использовали излучение лампы накаливания „Narva-100“ с непрерывным спектром, прошедшее через механический абтюратор. Сигнал регистрировался на частоте модуляции и спектральное разрешение во всех измерениях было не хуже $0.1 \mathrm{~nm}$. Дальнейшее усиление сигнала происходило в синхронном детекторе „Unipan-232“ с последующей регистрацией на компьютере.

Спектры фотолюминесценции (ФЛ) регистрировались при возбуждении светом лампы накаливания „Narva-100“, пропущенным через монохроматор МДР-12. Люминесценция образца поступала в оптический волновод, расположенный под углом $45^{\circ}$ к его поверхности на расстоянии $10 \mathrm{~mm}$ от нее, и анализировалась с помощью спектрометра МДР-6 и усилителя переменного сигнала „Unipan-232“, сопряженного с компьютером. При регистрации спектров возбуждения люминесценции длина волны на спектрометре МДР-6 фиксировалась на соответствующей полосе $Ф$ Л, а длина волны возбуждения на монохроматоре МДР-12 варьировалась в диапазоне видимых или инфракрасных длин волн. Иногда для заселения верхних энергетических уровней эрбия электронами одновременно с излучением лампы накаливания, пропущенным через монохроматор МДР-12, кристалл $\mathrm{Ca}_{1-x} \mathrm{Er}_{x} \mathrm{~F}_{2+x}$ облучался дополнительно непрерывным полупроводниковым лазером с длиной волны $970 \mathrm{~nm}$. Все измерения осуществлялись при температуре образцов $300 \mathrm{~K}$.

\section{3. Результаты и обсуждение}

Интересно исследование спектров поглощения полученных кристаллов $\mathrm{Ca}_{1-x} \mathrm{Er}_{x} \mathrm{~F}_{2+x}$ как в видимой, так и

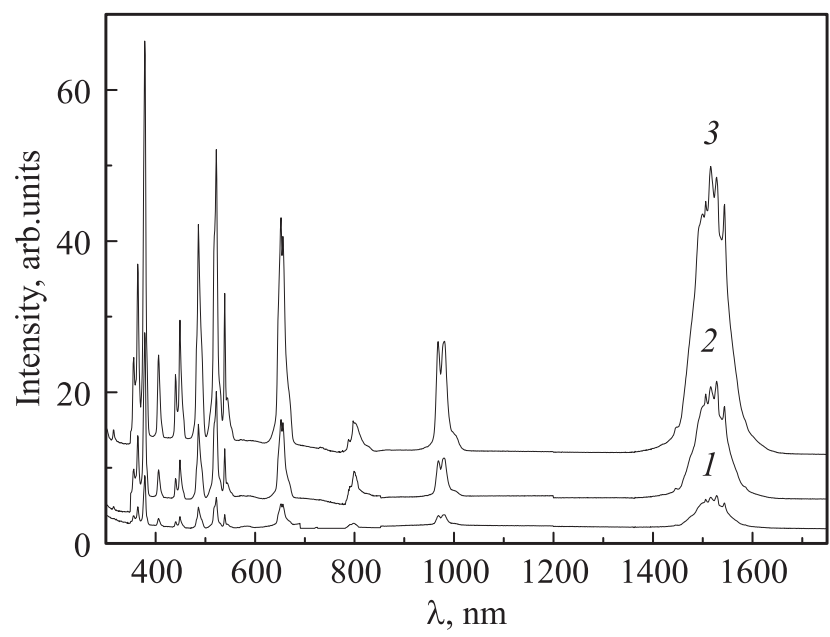

Рис. 1. Спектры поглощения кристаллов $\mathrm{Ca}_{1-x} \operatorname{Er}_{x} \mathrm{~F}_{2+x}$ для разных концентраций эрбия. $x: 1-0.005,2-0.010,3-$ $0.020(T=300 \mathrm{~K})$.

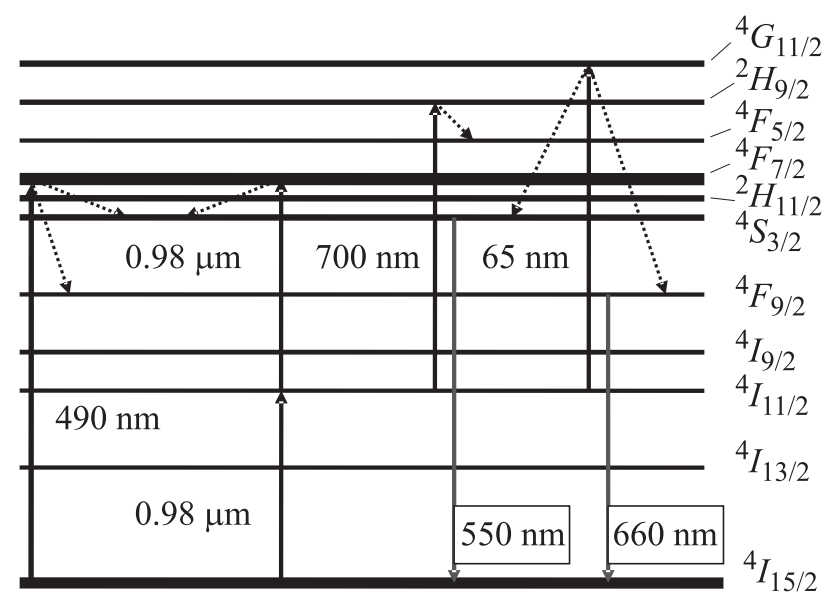

Рис. 2. Схема энергетических уровней иона эрбия $\mathrm{Er}^{3+}$ и соответствующих электронных переходов в процессе их двухфотонного возбуждения и излучательной рекомбинации кристаллов $\mathrm{Ca}_{1-x} \mathrm{Er}_{x} \mathrm{~F}_{2+x}$.

в инфракрасной области (рис. 1). Это помогает определить расположение энергетических уровней ионов эрбия в данном соединении по отношению основного нижнего уровня. На рис. 1 приведены спектры поглощения монохроматического света, прошедшего через кристаллы $\mathrm{Ca}_{1-x} \mathrm{Er}_{x} \mathrm{~F}_{2+x}$ с различной концентрацией РЗИ $x=0.005,0.010$ и 0.020 . Наличие множества пиков поглощения характерно для ионов эрбия. Ниже указано положение максимумов поглощения для фторида кальция, легированного эрбием, и соответствующие им возбужденные уровни иона $\mathrm{Er}^{3+}$, при переходах на которые из основного состояния ${ }^{4} I_{15 / 2}$ возникает поглощение света: $410 \mathrm{~nm}-{ }^{2} H_{9 / 2}, 450 \mathrm{~nm}-{ }^{4} F_{5 / 2}$, $490 \mathrm{~nm}-{ }^{4} F_{7 / 2}, 525 \mathrm{~nm}-{ }^{2} H_{11 / 2}, 545 \mathrm{~nm}-{ }^{4} S_{3 / 2}$ и $655 \mathrm{~nm}-{ }^{4} F_{9 / 2}$ (рис. 2). Указано центральное положение нескольких узких линий, которые обусловлены рас- 


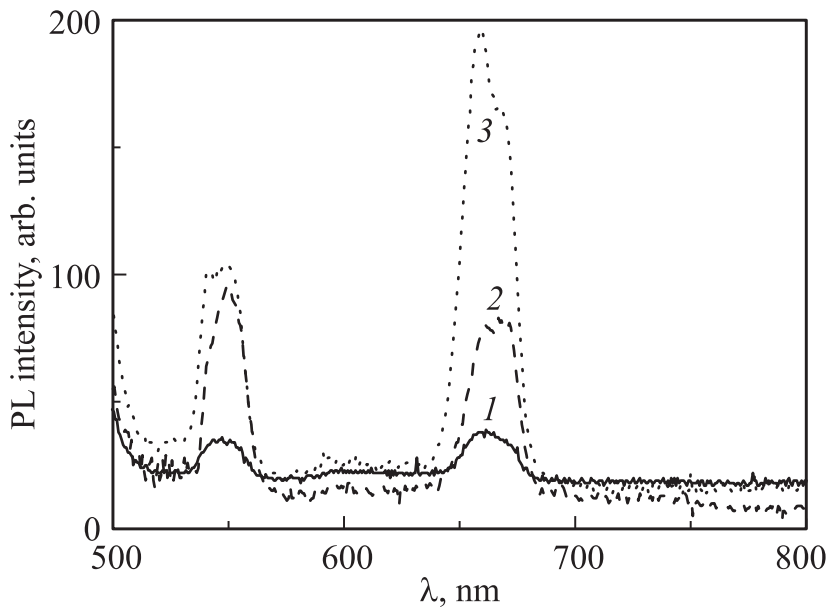

Рис. 3. Спектры ФЛ в видимой области кристаллов $\mathrm{Ca}_{1-x} \mathrm{Er}_{x} \mathrm{~F}_{2+x}$ для разных концентраций эрбия: $1-x=0.005$, $2-x=0.010,3-x=0.020$ при возбуждении излучением $490 \mathrm{~nm}(T=300 \mathrm{~K})$.

щеплением возбужденных состояний кристаллическим полем соединения. Отметим, что интенсивность пиков в поглощении увеличивается с ростом концентрации эрбия. В спектрах поглощения кристаллов $\mathrm{Ca}_{1-x} \mathrm{Er}_{x} \mathrm{~F}_{2+x}$, измеренных в инфракрасной области (рис. 1), хорошо различимы для максимальной концентрации по меньшей мере три максимума с длинами волн 800, 980 и $1520 \mathrm{~nm}$. При этом, максимум $800 \mathrm{~nm}$ можно связать с переходами ${ }^{4} I_{15 / 2}-{ }^{4} I_{9 / 2}$, а максимумы $980 \mathrm{~nm} \mathrm{и} 1520 \mathrm{~nm}-$ с переходами электронов ${ }^{4} I_{15 / 2}-{ }^{4} I_{11 / 2}$ и ${ }^{4} I_{15 / 2}-{ }^{4} I_{13 / 2}$ внутри ионов эрбия.

Для регистрации полос видимого свечения кристаллов $\mathrm{Ca}_{1-x} \mathrm{Er}_{x} \mathrm{~F}_{2+x}$ мы использовали возбуждение в одну из обнаруженных ранее полос поглощения синим светом, пропущенным через монохроматор, с длиной волны $490 \mathrm{~nm}$ (рис. 3). Отметим наличие в спектрах ФЛ люминофора, кроме характерных линий эрбия в красной области с длинами волн 665 и $655 \mathrm{~nm}$, двух довольно узких полос люминесценции в зеленой (с максимумами 537 и $545 \mathrm{~nm}$ ) области спектра. Эти особенности красного свечения могут быть связаны с излучательными переходами электронов с возбужденного уровня ${ }^{4} F_{9 / 2}$ на расщепленный кристаллическим полем нижний основной уровень ${ }^{4} I_{15 / 2}$ ионов эрбия (рис. 2). Интенсивный пик зеленого свечения с максимумом $545 \mathrm{~nm}$, соответствует переходам электронов с возбужденного уровня ${ }^{4} S_{3 / 2}$ на основной уровень ${ }^{4} I_{15 / 2}$. В то время как полоса $537 \mathrm{~nm}$ обусловлена переходами с уровня ${ }^{2} H_{11 / 2}$ на нижний уровень ${ }^{4} I_{15 / 2}$ ионов эрбия. Выше речь идет о стоксовой фотолюминесценции, поскольку энергия фотонов возбуждения была выше, чем энергия регистрируемых фотонов видимого спектра.

На рис. 4 и 5 показаны спектры возбуждения линий люминесценции 550 и $655 \mathrm{~nm}$ кристаллов $\mathrm{Ca}_{1-x} \mathrm{Er}_{x} \mathrm{~F}_{2+x}$ в области энергии фотонов большей, чем энергия фотонов люминесценции. Можно видеть, что спектр воз- буждения ионов $\mathrm{Er}^{3+}$ в основном состоит из нескольких серий узких полос с центрами при длинах волн 385 , $415,455,490,525$ и $545 \mathrm{~nm}$ соответственно. Эти полосы возбуждения возникают при поглощении падающего излучения лампы накаливания ионами эрбия, что приводит к переходам электронов из основного ${ }^{4} I_{15 / 2}$ состояния на возбужденные энергетические уровни, расщепленные кристаллическим полем. Согласно литературным данным, эти полосы возбуждения возникают при длинах волн и при переходах, аналогичных указанным выше при описании спектров поглощения (рис. 1). Отличием спектров возбуждения линий люминесценции 550 и $655 \mathrm{~nm}$ является появление на последних дополнительных длинноволновых пиков с длинами волн $545 \mathrm{~nm}$, которые соответствуют переходам электронов с основного нижнего состояния на возбужденные энергетические уровни -

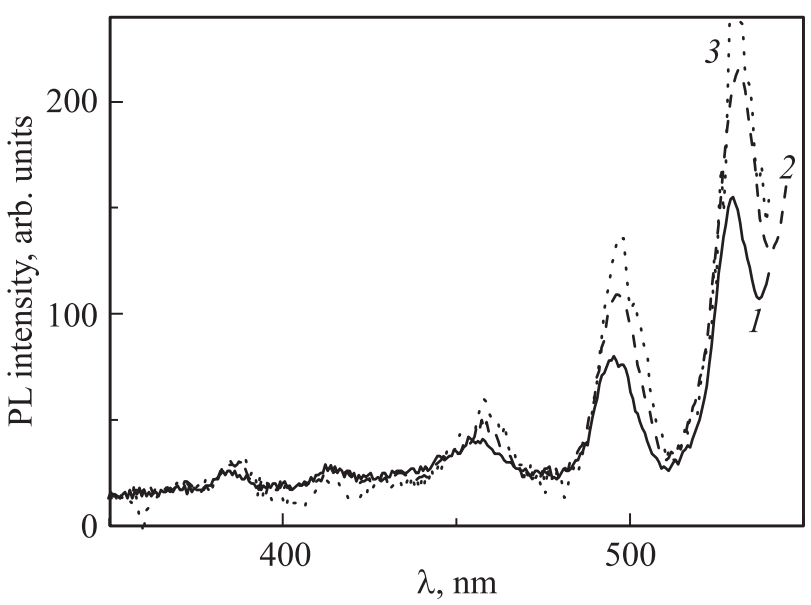

Рис. 4. Спектры возбуждения в видимой области линии ФЛ $550 \mathrm{~nm}$ кристаллов $\mathrm{Ca}_{1-x} \mathrm{Er}_{x} \mathrm{~F}_{2+x}$ для разных концентраций эрбия: $1-x=0.005,2-x=0.010,3-x=0.020$ при $T=300 \mathrm{~K}$.

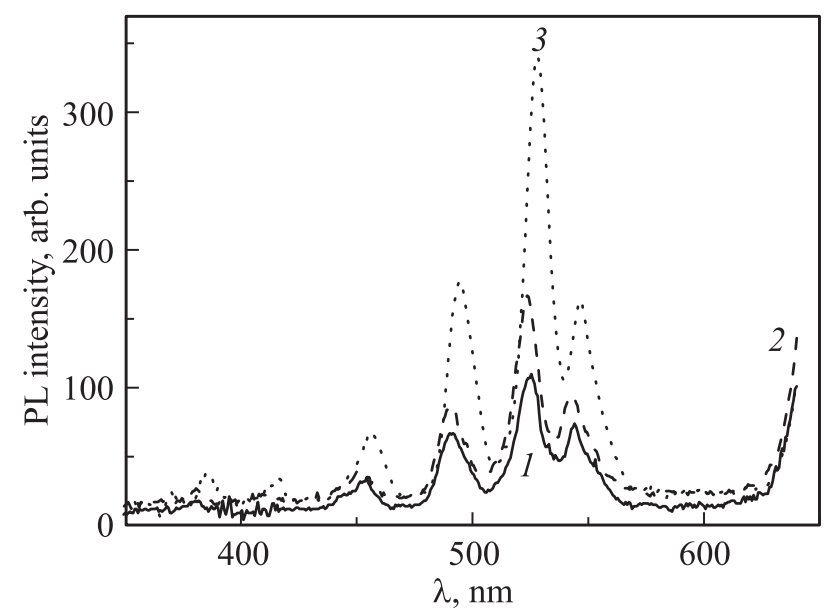

Рис. 5. Спектры возбуждения в видимой области линии ФЛ $655 \mathrm{~nm}$ кристаллов $\mathrm{Ca}_{1-x} \mathrm{Er}_{x} \mathrm{~F}_{2+x}$ для разных концентраций эрбия: $1-x=0.005,2-x=0.010,3-x=0.020$ при $T=300 \mathrm{~K}$. 

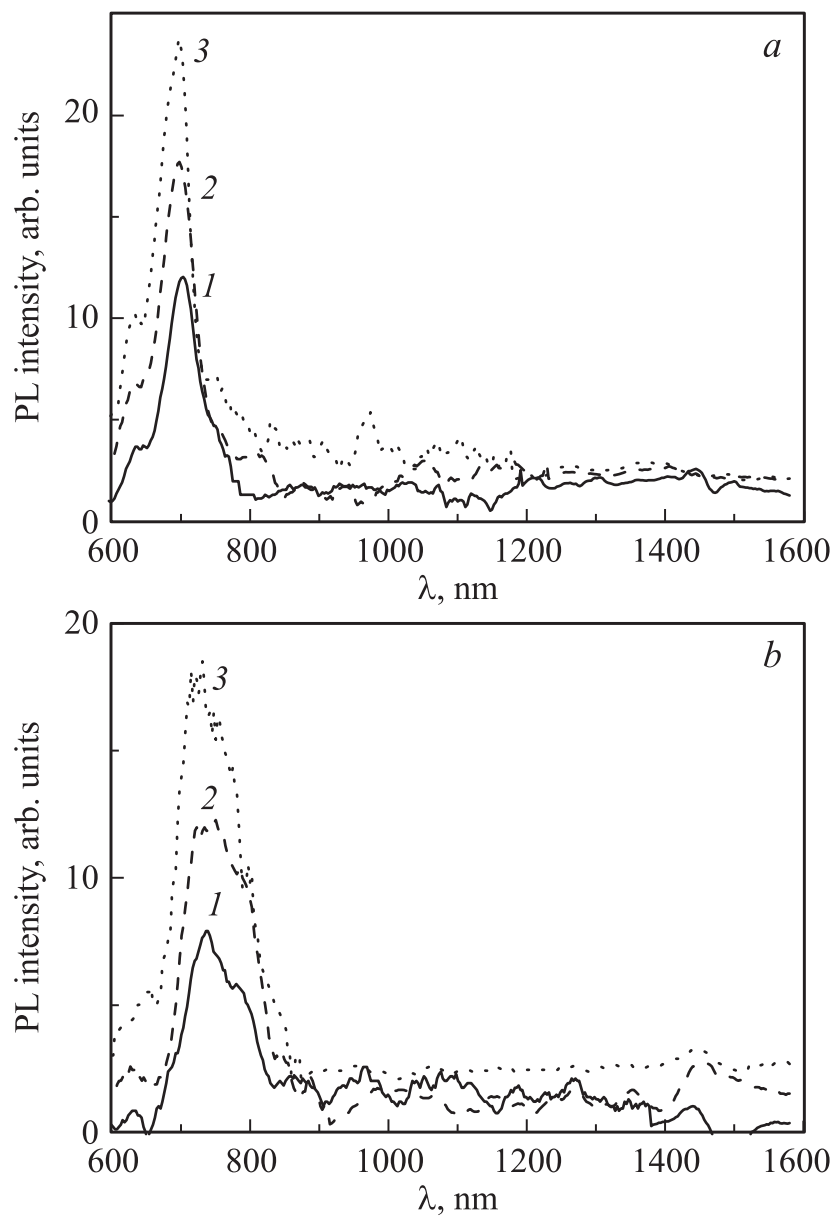

Рис. 6. Спектры возбуждения в инфракрасной области линии ФЛ $550 \mathrm{~nm}$ кристаллов $\mathrm{Ca}_{1-x} \mathrm{Er}_{x} \mathrm{~F}_{2+x}$ для разных концентраций эрбия: $1-x=0.005,2-x=0.010,3-x=0.020$ без лазерной $(a)$ и с лазерной $(b)$ подсветкой при $T=300 \mathrm{~K}$.

${ }^{4} S_{3 / 2}$. Можно отметить также рост интенсивности линий возбуждения с ростом концентрации эрбия в данном материале, причем яркость красной полосы свечения возрастает больше по сравнению с зеленой (рис. 3). Поэтому если исследованное соединение $\mathrm{Ca}_{1-x} \mathrm{Er}_{x} \mathrm{~F}_{2+x}$ имеет зеленый цвет свечения (рис. 3) при концентрации эрбия $x=0.005$, то при концентрации примеси $x=0.020$ оно будет красным.

Рис. 6, $a$ показывает спектры возбуждения линии $550 \mathrm{~nm}$ антистоксовой люминесценции кристаллов $\mathrm{Ca}_{1-x} \mathrm{Er}_{x} \mathrm{~F}_{2+x}$ в области энергии фотонов меньшей, чем энергия фотонов люминесценции. Хорошо различим широкий пик возбуждения с максимумом $700 \mathrm{~nm}$ и плече в области $655 \mathrm{~nm}$. Кроме того, для максимальной концентрации эрбия виден максимум при $980 \mathrm{~nm}$ (кривая 3), который обусловлен двумя последовательными процессами поглощения инфракрасных фотонов с переходами ${ }^{4} I_{15 / 2}-{ }^{4} I_{11 / 2}$ и далее ${ }^{4} I_{11 / 2}-{ }^{4} F_{7 / 2}$ внутри ионов эрбия (рис. 2). В нашем случае речь идет именно об оптическом поглощении двух ИК-фотонов, а не об безызлучательном обмене энергии между возбужден- ными ионами. Мы использовали в эксперименте механический абтюратор для модуляции падающего пучка света с частотой $230 \mathrm{~Hz}$. На осциллографе интенсивность зеленого свечения $550 \mathrm{~nm}$ имела временную зависимость, аналогичную временной развертке падающего ИК-возбуждения с точностью менее $1 \mathrm{~ms}$. Если бы имел место безызлучательный перенос энергии между двумя ${ }^{4} I_{11 / 2}$ состояниями ионов эрбия при возбуждении антистоксовой люминесценции, то ее время затухания было бы равно $4.5 \mathrm{~ms}$ времени жизни метастабильного ${ }^{4} I_{11 / 2}$ состояния [7]. Что касается максимумов антистоксового возбуждения при 655 и $700 \mathrm{~nm}$ (рис. 6,a), то первый из них возникает при переходах электронов из основного состояния ${ }^{4} I_{15 / 2}-{ }^{4} F_{9 / 2}$, их дальнейшей релаксацией на метастабильный уровень ${ }^{4} I_{11 / 2}$ и переходом ${ }^{4} I_{11 / 2}-{ }^{4} G_{11 / 2}$ при поглощении второго фотона (рис. 2) [8]. Второй фотон может быть меньшей энергии $(700 \mathrm{~nm})$ и тогда вторым переходом внутри ионов эрбия будет ${ }^{4} I_{11 / 2}-{ }^{2} H_{9 / 2}$. Мы вообще можем использовать для заселения метастабильных состояний ${ }^{4} I_{11 / 2}$ второй источник света - непрерывный полупроводниковый лазер с длиной волны излучения $970 \mathrm{~nm}$ и оптической мощностью $1 \mathrm{~W}$. Тогда спектр возбуждения антистоксовой люминесценции $550 \mathrm{~nm}$ при сканировании вторым ИК-пучком света будет представлять собой широкую полосу с максимумом $730 \mathrm{~nm}$ (рис. 6, $b$ ).

То, что в указанных двух фотонных переходах задействован метастабильный уровень ${ }^{4} I_{11 / 2}$, а не более низкий ${ }^{4} I_{13 / 2}$ подтверждают спектры антистоксовой люминесценции кристаллов $\mathrm{Ca}_{1-x} \mathrm{Er}_{x} \mathrm{~F}_{2+x}$ для разных концентраций эрбия: $1-x=0.005 ; 2-x=0.010 ; 3-$ $x=0.020$ при возбуждении излучением $700 \mathrm{~nm}$ (рис. 7). Они состоят из трех широких полос с максимумами 450,550 и $660 \mathrm{~nm}$. Если зеленую и красную полосы мы видели раньше (рис. 3) при возбуждении $490 \mathrm{~nm}$, то синяя полоса возникает при переходах с уровней ${ }^{4} F_{5 / 2}$ на основной нижний уровень ионов эрбия. Однако

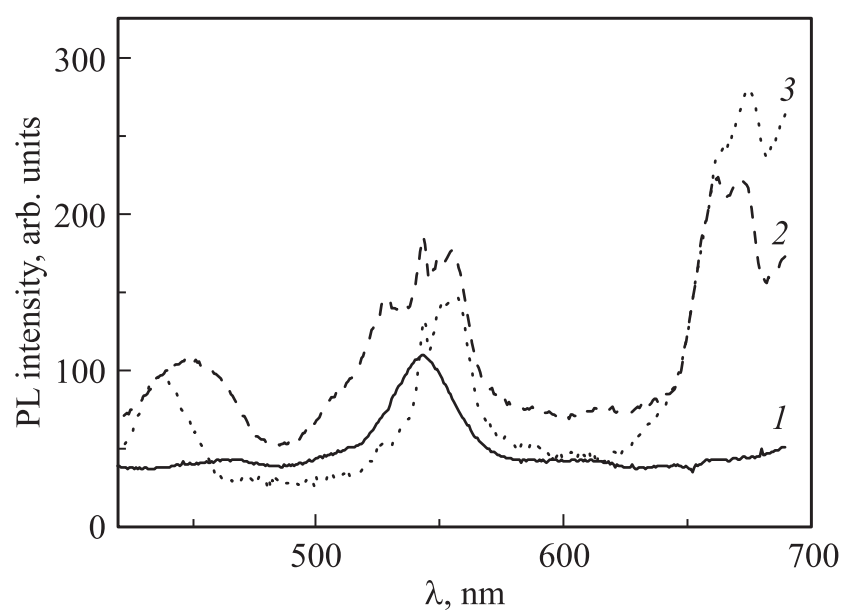

Рис. 7. Спектры ФЛ в видимой области кристаллов $\mathrm{Ca}_{1-x} \mathrm{Er}_{x} \mathrm{~F}_{2+x}$ для разных концентраций эрбия: $1-x=0.005$ $2-x=0.010,3-x=0.020$ при возбуждении излучением $700 \mathrm{~nm}(T=300 \mathrm{~K})$. 
второй фотон $700 \mathrm{~nm}$ может забросить на столь высокий уровень электрон только с уровня ${ }^{4} I_{11 / 2}$, а не с ${ }^{4} I_{13 / 2}$ (рис. 2).

Ранее авторам [9] удалось наблюдать лазерную генерацию в зеленой области кристаллов $\mathrm{Y}_{3} \mathrm{Al}_{5} \mathrm{O}_{12}: \mathrm{Er}$ при одновременной накачке непрерывным криптоновым лазером с длиной волны $647 \mathrm{~nm}$ и импульсным титан-сапфировым с длиной волны $810 \mathrm{~nm}$. В качестве метастабильного возбужденного уровня также как и у нас служил ${ }^{4} I_{11 / 2}$ уровень ионов эрбия. В работе [10] подробно описана модуляционная методика двухлучевого поглощения, позволившая измерить и сравнить сечения оптического поглощения при переходах электрона с основного и с метастабильных возбужденных состояний ионов эрбия в различных кристаллах. Показано, что эти сечения имеют сравнимую величину, а интенсивность соответствующих линий зависит от интенсивности накачки. С увеличением накачки заселенность возбужденных уровней возрастает и в спектре поглощения начинают преобладать переходы с метастабильных состояний. Это в свою очередь ведет к росту интенсивностей линий видимой антистоксовой люминесценции по сравнению с ИК-люминесценцией. В наших работах мы наблюдали аналогичную картину для люминофоров $\mathrm{Y}_{1.80} \mathrm{Er}_{0.10} \mathrm{Yb}_{0.10} \mathrm{O}_{2} \mathrm{~S}$ и $\mathrm{Y}_{1.90} \mathrm{Er}_{0.10} \mathrm{O}_{3} \mathrm{c}$ дополнительным легированием иттербием $[11,12]$. Можно утверждать в данном случае также о поглощении ИК-света при переходах электронов с метастабильных возбужденных уровней внутри ионов $\mathrm{Er}^{3+}$ на более высокие состояния. Этот перенос энергии происходит безызлучательным образом, когда концентрация эрбия и заселенность метастабильных уровней энергии ${ }^{4} I_{11 / 2}$ ионов эрбия велика, создавая условия для переходов электрона на более высокоэнергетические уровни при дипольном взаимодействии возбужденных ионов. Поглощение второго ИК-фотона тогда идет на соседнем ионе. Этот фотон имеет такую же энергию, как и первый в случае использования одного источника ИК-спектра для возбуждения антистоксовой люминесценции. Если использовать два ИК-источника, то последовательно поглощаемые фотоны могут иметь различные энергии. При этом, интенсивность антистоксовой люминесценции гораздо выше, когда ион эрбия последовательно поглощает два ИК-фотона не с одинаковой энергией $1.26 \mathrm{eV}$ $(980 \mathrm{~nm})$, а с разной. Поэтому интенсивность пиков возбуждения 655 и $700 \mathrm{~nm}$, выше, чем у пика $980 \mathrm{~nm}$ (рис. 6, a, кривая 3).

\section{4. Заключение}

Методом Бриджмена получены кристаллы $\mathrm{Ca}_{1-x} \operatorname{Er}_{x} \mathrm{~F}_{2+x}$ с разной концентраций эрбия: 1 $x=0.005 ; 2-x=0.010 ; 3-x=0.020$. Проведен анализ спектров поглощения, возбуждения и фотолюминесценции данного соединения при стоксовом и антистоксовом механизме возбуждения. Показано, что антистоксовая люминесценция фторида кальция, легированного эрбием, имеет большую интенсивность при разной энергии фотонов инфракрасной подсветки и для больших концентраций РЗИ. Определены резонансные длины волн ИК-фотонов и схемы энергетических переходов внутри ионов эрбия (рис. 2) для двухфотонного возбуждения видимого свечения кристаллов $\mathrm{Ca}_{1-x} \mathrm{Er}_{x} \mathrm{~F}_{2+x}$.

\section{Список литературы}

[1] R. Brede, E. Heumann, J. Koetke, T. Danger, G. Huber, B. Chai. Appl. Phys. Lett. 63, 2030 (1993).

[2] F. Auzel. Chem. Rev. 104, 139 (2004).

[3] L.A. Bausa, G. Lifante, E. Daran, P.L. Pernas. Appl. Phys. Lett. 68, 3242 (1996).

[4] P. Rogin, J. Hulliger. J. Cryst. Growth 172, 200 (1997).

[5] С.Х. Батыгов, Л.А. Кулевский, А.М. Прохоров, А.Д. Савельев, В.В. Смирнов, В.В. Осико. Квант. электроника 1, 2633 (1974).

[6] Д.Н. Каримов, О.Н. Комарькова, Н.И. Сорокин, В.А. Бежанов, С.П. Чернов, П.А. Попов, Б.П. Соболев. Кристаллография 55, 556 (2010).

[7] А.М. Прохоров. Справочник по лазерам. Сов. радио, М. (1978). T. 2, 503 c.

[8] P.L. Boulanger, J.L. Doualan, S. Girard, J. Margerie, R. Moncorge. Phys. Rev. B 60, 11380 (1999).

[9] R. Brede, E. Heumann, J. Koetke, T. Danger, G. Huber. Appl. Phys. Lett. 63, 2030 (1993).

[10] J. Koetke, G. Huber. Appl. Phys. B 61, 151 (1995).

[11] А.Н. Грузинцев. Неорган. материалы 50, 885 (2014).

[12] А.Н. Грузинцев. Неорган. материалы 50, 64 (2014). 